\title{
IDENTIFICATION OF $P$. brasiliensis IN THE HEART AND EVALUATION OF CARDIAC INVOLVEMENT OF BALB/c MICE IN EXPERIMENTAL PCM
}

Junnia Alvarenga de Carvalho Oliveira ${ }^{1}$; Elis Araújo Morais ${ }^{1}$; Eliza Mathias Melo ${ }^{1}$; Pricila da Silva Cunha ${ }^{1}$; Camila Medeiros Carneiro ${ }^{2}$; Luciana Nascimento Soares de Sá2; Estefânia Mara do Nascimento Martins ${ }^{1}$; Alfredo Miranda de Goes $^{1}$; Maria Aparecida de Resende Stoianoff ${ }^{1}$.

Universidade Federal de Minas Gerais ${ }^{1}$; Centro Universitário de Belo Horizonte ${ }^{2}$. Email: junnia@ outlook.com

\section{INTRODUCTION}

Paracoccidioidomycosis is a systemic disease, endemic in Latin America, caused by dimorphic fungi of Paracoccidioides genus. Even though the primary pathway of infection is pulmonary, by inhalation of conidia, several anatomical sites may be affected by lymphoematogenic dissemination, including the heart. Studies demonstrate the complexity of the $P$. brasiliensis caused disease and reveal a necessity to investigate the infection sites of these microorganisms, because the involvement may be underdiagnosed.

The aim of this work was to identify and characterize fungal colonization in the heart of $P$. brasiliensis infected mice.

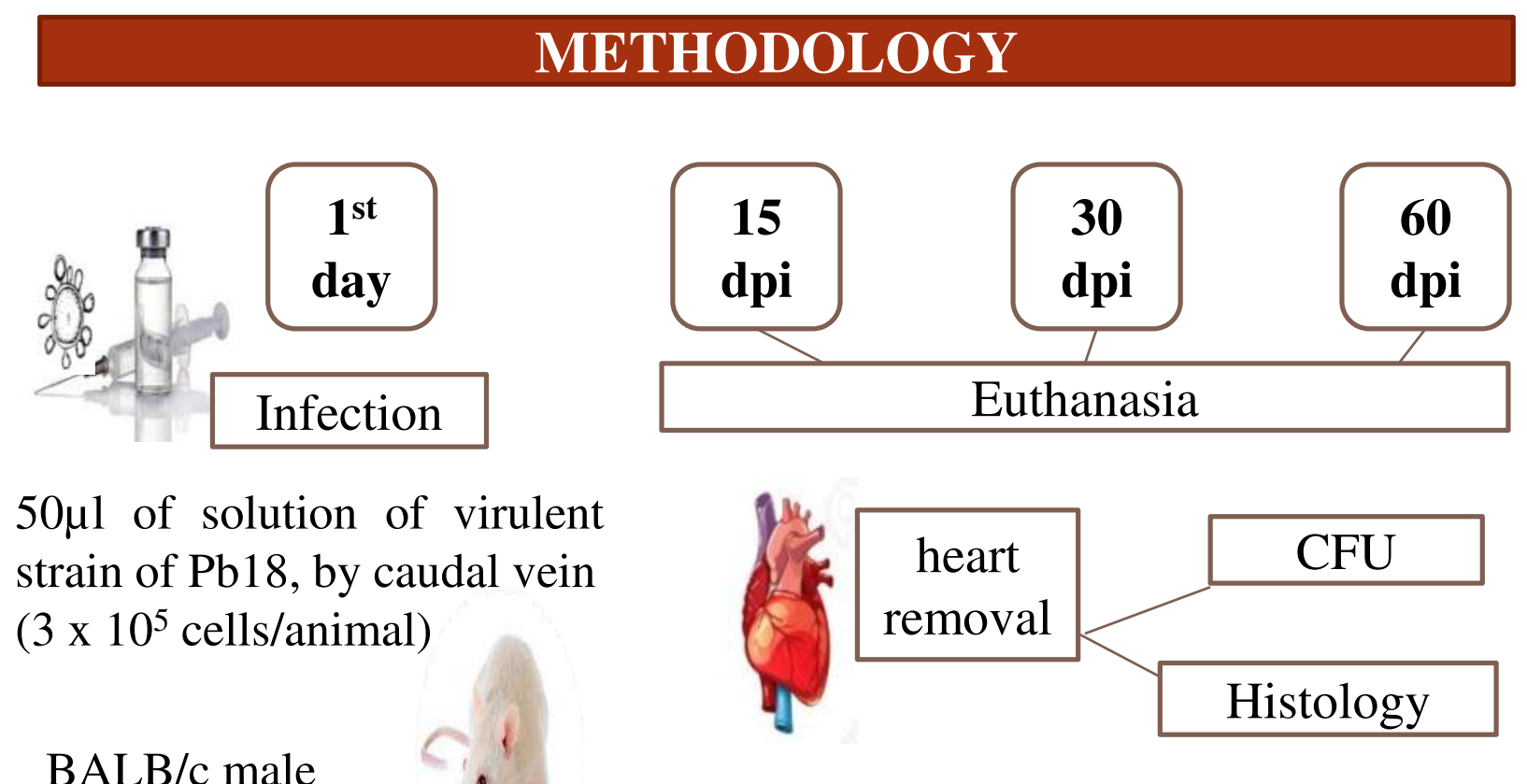

BALB/c male CEUA $321 / 2012$

\section{RESULTS}

P. brasiliensis was recovered from cardiac tissue 15, 30 and 60 days after experimental infection (figure 1). Heart tissue harvested from mice 30 days after infection was stained using Grocott and showed fungal presence inside the tissue (figure 2).

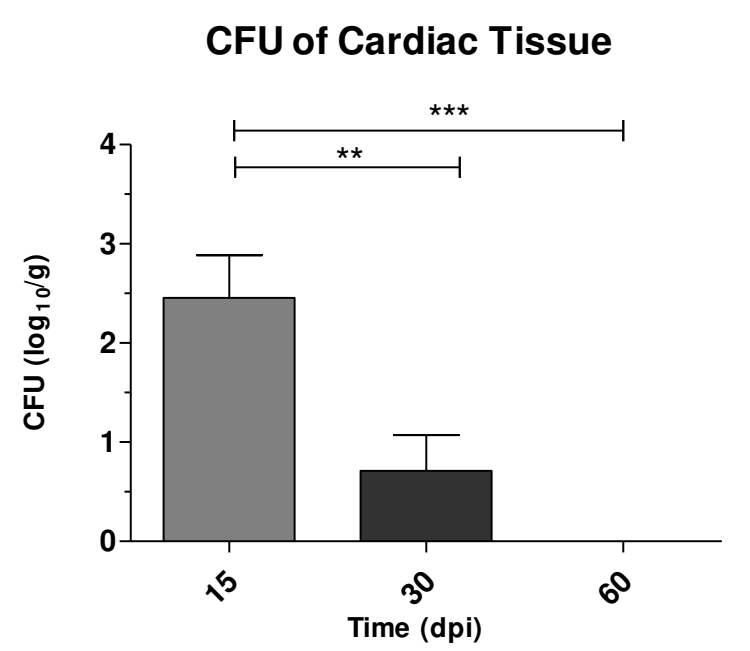

Figure 1. Colony forming units (CFU) recovered from cardiac and pulmonary tissue of animals after 15,30 and 60 days of infection by $P$. brasiliensis, via caudal vein. Histograms represent the mean \pm standard deviation of $\mathrm{CFUs}$ and the values are expressed as $\log 10(\mathrm{n}=9)$. * represents $\mathrm{p}<0.05$ or $* * *$ represents $\mathrm{p}<0.001$. Test 2way ANOVA and post-test Bonferroni.

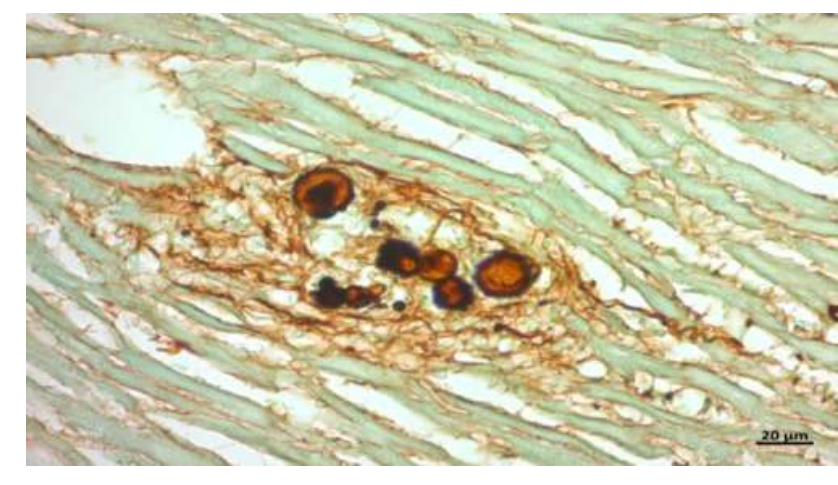

Figure 2. Grocott staining of mice cardiac tissue 30 days after $P$. brasiliensis infection. The presence of brown rounded cells indicates fungal cells inside the tissue. Scale: $100 \mu \mathrm{m}$.

Hematoxylin and Eosin (HE) and Masson's Trichrome staining were used to evaluate inflammatory process, granuloma formation and connective tissue deposition 15, 30 and 60 days after infection. Multifocal granuloma consisting of interstitial inflammatory infiltrates are present. In these inflammatory sites, circular birefringent cells were detected, varying between 6 and $20 \mu \mathrm{m}$ in diameter, characteristic of $P$. brasiliensis (figure 3). Granulomatous reactions and fungal cells are surrounded and interspersed by fibrous connective tissue, in addition to the presence of collagen fibers (Figure 4).

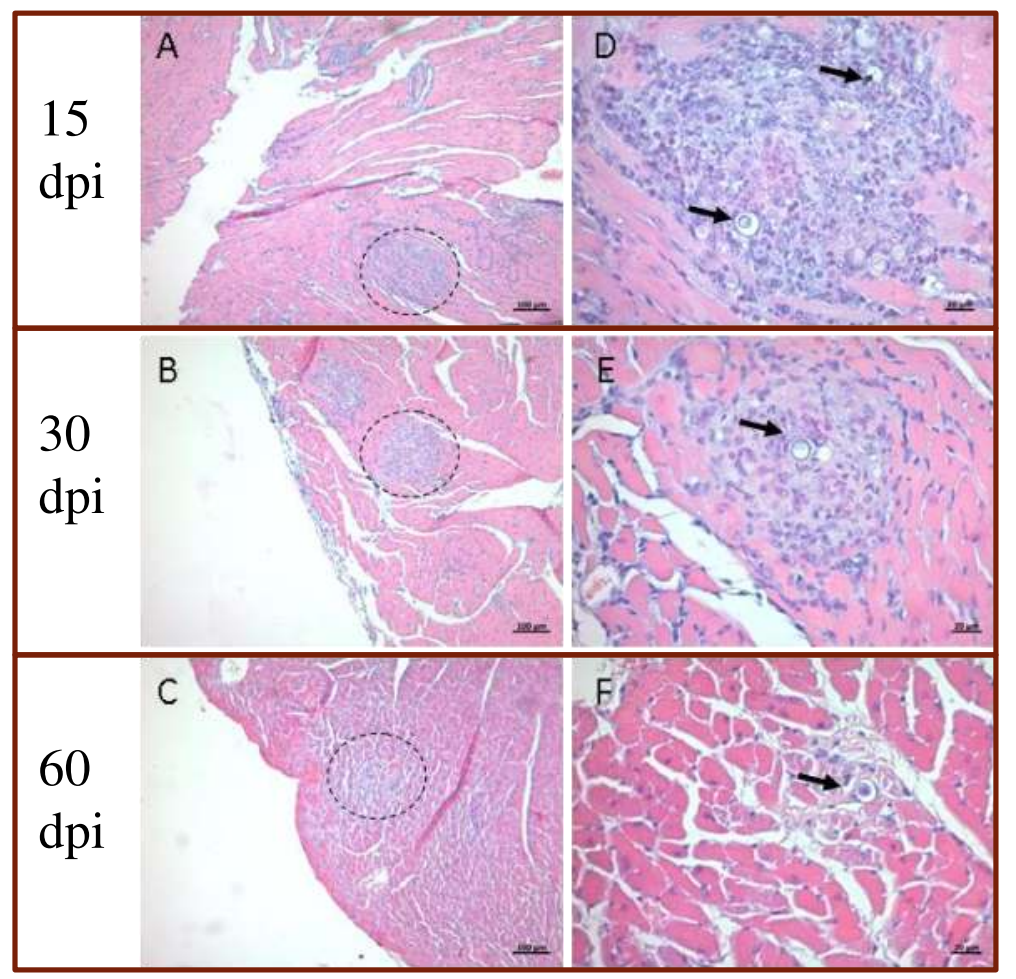

Figure 3. HE staining of mice cardiac tissue processed 15,30 and 60 days after $P$. brasiliensis infection. Photomicrography at lower magnification (A, B and C) scale: $100 \mu \mathrm{m}$. At higher magnification (D, $\mathrm{E}$ and $\mathrm{F}$ ) scale: $20 \mu \mathrm{m}$. Dotted circles indicate inflammatory infiltrate and black arrows indicate fungal cells localized in the tissue.

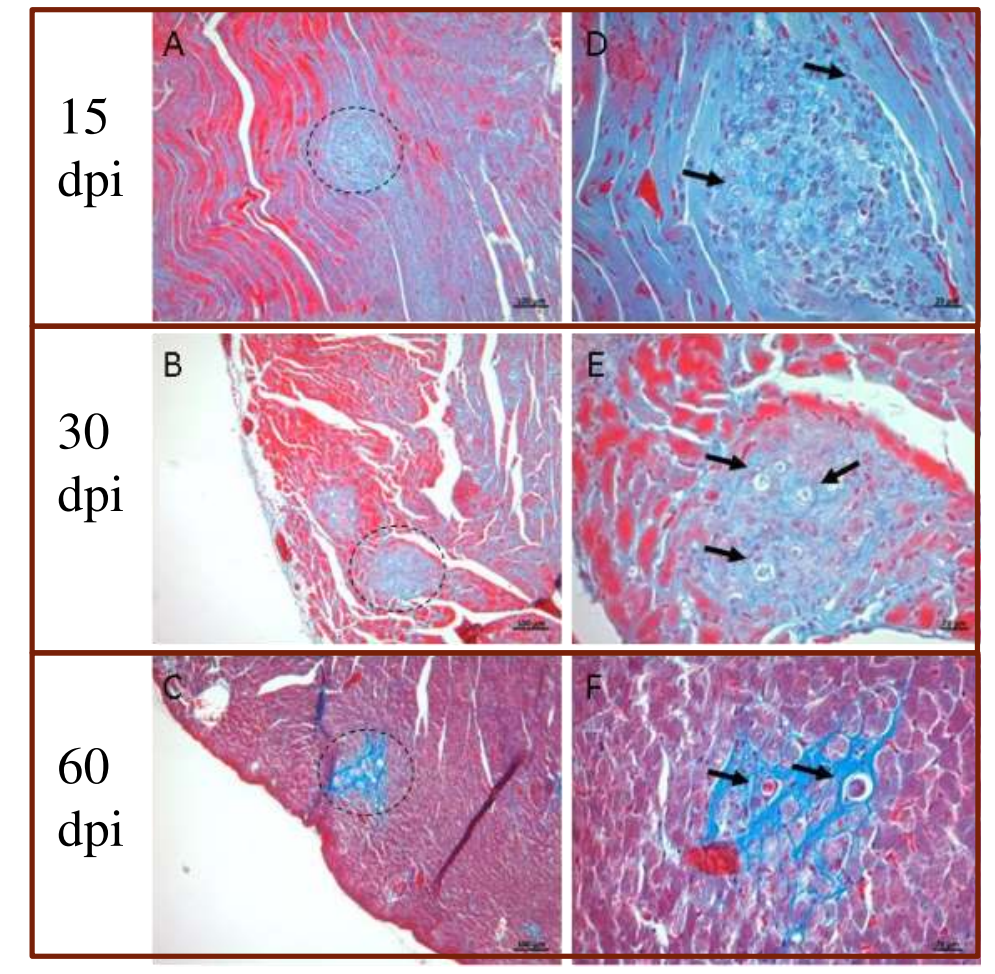

Figure 4. Masson's trichrome processed 15,30 and 60 days after $P$ brasiliensis infection. Photomicrography at lower magnification (A, B and C) scale: 100 $\mu \mathrm{m}$. At higher magnification (D, E and F) scale: $20 \mu \mathrm{m}$. Dotted circles indicate collagen fibers infiltrate (blue) and black arrows indicate fungal cells localized in the tissue.

\section{CONCLUSION}

P. brasiliensis has capacity to infect cardiac tissue, to colonize and to generate inflammatory responses characteristic of the disease such as granulomas formation and collagen deposition which may compromise cardiac function and aggravate clinical condition of patients. 